\title{
Intellectual disability and computers in therapy: Views of service users and clinical psychologists
}

\author{
Leen Vereenooghe ${ }^{1}$, Lina Gega ${ }^{2}$, \& Peter E. Langdon ${ }^{3}$ \\ ${ }^{1}$ Department of Psychology, Bielefeld University, Bielefeld, Germany \& Department of Clinical Psychology, University of East Anglia, Norwich, \\ United Kingdom \\ ${ }^{2}$ Department of Health Sciences \& Hull York Medical School, University of York, York, United Kingdom \\ ${ }^{3}$ Tizard Centre, University of Kent, Kent, United Kingdom \& Broadland Clinic, Hertfordshire Partnership University NHS Foundation Trust - \\ Norfolk, United Kingdom
}

\begin{abstract}
Digital media have increased the accessibility of psychological therapies for the general population, but not for people with intellectual disability (ID), despite their greater mental health needs. This study explores and compares the views of service users and clinicians on how computers can be integrated in psychological therapies for people with ID who are traditionally under-represented in mainstream services. We conducted indepth unstructured interviews with three clinicians who had experience of working with people with ID and with three adults with ID who have experienced computerised training in cognitive behaviour therapy skills. The interviews explored the a) potential functions and benefits, b) anticipated challenges and barriers, and c) required design features of computers in therapy for people with ID. We used inductive coding to identify independent themes in the responses of clinicians and service users, and then compared the emerging themes between the two sets of participants to arrive at common themes. Six common themes emerged from service user and clinician responses: confidentiality of personal information and online applications, barriers in the communication with the therapist, value of therapist and personal contact, access to computer technologies, engagement potential of computer programmes and home practice. Three further themes were specific to clinician responses: patient suitability for computerised approaches, clinician distrust of computerised interventions, and involving a third party. Computer technologies open up possibilities for psychological therapy with people with ID by helping them overcome in-session communication difficulties and practise skills at home. On-screen pictures, interactive games, symbols, sign language and touch-screen are key design features to help engagement. The main challenges are clinician-reported difficulties in their own capacity and capability to access and use computers and in fitting computers into their own defined roles.
\end{abstract}

Keywords: Cognitive Behaviour Therapy; intellectual disability; technology; mental health; online interventions

\section{Introduction}

The evidence for the efficacy and acceptability of internet-delivered psychological interventions for children and adults with mental health problems is growing steadily (Andersson, 2009; Newby, Twomey, Li, \& Andrews, 2016; Pennant et al., 2015; Richards, Richardson, Timulak, \& McElvaney, 2015); yet people with intellectual disability (ID) have been consistently excluded from this area of research. People with ID present with a below average level of intellectual functioning, as indicated by an IQ below 70, and impairments in their adaptive functioning, 
which have an age of onset before 18 years of age (World Health Organisation, 1992). The term "intellectual disability" as a social-ecological construct in relation to someone's functioning moves away from disability as a person-centred deficit trait and highlights the role of social and environmental factors in impairing or enabling the functioning of someone with ID (Schalock et al, 2007).

While certain biological, psychological and social factors associated with having an ID increase their risk of developing mental health problems, compared to people without ID, (Cooper, Smiley, Morrison, Williamson, \& Allan, 2007; Emerson \& Hatton, 2007), their access to psychiatric services is markedly lower (Bhaumik, Tyrer, Mcgrother, \& Ganghadaran, 2008; Chinn, Abraham, Burke, \& Davies, 2014). Multiple factors are associated with this reduced access to and use of mental health services by people with ID, including barriers in verbal and cognitive ability (Willner, 2006) and practitioner confidence (Mesa \& Tsakanikos, 2014; Rose, 2013). The limited provision of psychological therapies for people with ID may also be due to the limited evidence-base, which is short in robust designs and controlled intervention studies (Burke, 2014; Vereenooghe \& Langdon, 2013).

To promote the uptake of psychological interventions by people with disabilities, including those with ID, service providers need to make reasonable adjustments to facilitate equal access to their services (Department of Health, 2009). For people with ID, these adjustments include more frequent and shorter therapy sessions, simpler language and therapeutic methods, more therapist directivity, and greater interactivity, for example through the use of games (Hurley, Tomasulo, \& Pfadt, 1998; Whitehouse, Tudway, Look, \& Stenfert-Kroese, 2006). The impact of these adjustments remains unclear, as the availability of systematically analysed data regarding potential changes in the uptake of these services by people with ID is limited (Taylor \& Knapp, 2013).

With the rise of new technologies come new possibilities to promote the accessibility of health care interventions, and computers have already proven their potential as a means of augmentative and alternative communication. Furthermore, computerised and internet-delivered interventions are promising assistive technologies in training vocational skills, problem-solving skills, and social skills (Dattilo, Williams, \& Cory, 2003; Standen \& Brown, 2005).

Brief computerised training programmes may improve the ability of people with mild to moderate ID to gain some of the basic skills to engage in cognitive behaviour therapy (CBT; Vereenooghe, Gega, Reynolds, \& Langdon, 2016; Vereenooghe, Reynolds, Gega, \& Langdon, 2015). This is important because CBT has the potential to reduce anger problems and depression in people with ID (Vereenooghe \& Langdon, 2013) but its underlying theoretical rationale is difficult to grasp (Dagnan, Mellor, \& Jefferson, 2009; Joyce, Globe, \& Moody, 2006; Oathamshaw \& Haddock, 2006; Reed \& Clements, 1989).

It is not clear whether and how computers can have an added value in therapy for people with ID over and above the usual adjustments made currently in services. We also need to know what may prevent the use of computers in routine practice and how computer programmes should look and function in order to have a therapeutic value for this population. The objectives of this study are to identify the (a) functions and benefits, (b) challenges and barriers, and (c) required design features of computers in therapy for people with ID. The study explores and compares the views of service users with ID, as well as the expectations of clinicians who routinely work with people with ID.

\section{Methods}

\section{Participants}

We interviewed three service users with ID and three clinical psychologists, representing both genders, a range of ages, different levels of working experience for the clinicians, and different levels of ID for the service users.

The service users were recruited from a sample of participants who had previously taken part in a computerised therapy skills training session (Vereenooghe et al., 2016). Service users had confirmed ID from their care coordinator (doctor or psychologist), were over 18 years old, and had sufficient verbal and cognitive skills to understand both the purpose of the research and to give informed consent. We approached five service users with ID to take part in our interviews, but only three of them, a man and two women (described in Table 1), were 
able to give sufficient verbal responses for analysis. The three service users differed considerably in their verbal ability and response length.

We also interviewed three clinical psychologists (one man and two women) who had experience working with people with ID across all ages (Table 2).

Table 1. Service User Characteristics.

\begin{tabular}{llllll}
\hline User (U) & Age & Gender & Full-scale IQ & Verbal IQ & Familiarity with computers \\
\hline U1 & 43 & Male & 56 & 54 & Owns a desktop and a smartphone \\
U2 & 29 & Female & 57 & 60 & Owns a tablet and a smartphone \\
U3 & 31 & Female & 67 & 70 & Owns a laptop and a smartphone \\
\hline
\end{tabular}

Table 2. Clinician Characteristics.

\begin{tabular}{llllll}
\hline Clinician (C) & Age & Gender & $\begin{array}{l}\text { Area of work with } \\
\text { ID }\end{array}$ & $\begin{array}{l}\text { Years work } \\
\text { with ID }\end{array}$ & Use of computers in therapy \\
\hline C1 & 31 & Male & Adults & 3 & Tablet to show videos \\
C2 & 52 & Female & $\begin{array}{l}\text { Adults } \\
\text { Children and }\end{array}$ & 19 & $\begin{array}{l}\text { None } \\
\text { Emailing and playing the child's own } \\
\text { C3 }\end{array}$ \\
\hline
\end{tabular}

\section{Data Collection}

As computer programmes are not currently used in routine therapy services for people with ID, the interview questions for both service users and clinical psychologists intended to elicit their views regarding the potential of computers, in terms of a) their desired functions and benefits, b) anticipated challenges and barriers, and c) important design features, to be used for therapy with people with ID. The interviews took 30-45 minutes to complete and took place in either a quiet room at the day service for the service users or at their workplace for the clinicians. The interviews were recorded using a digital voice recorder and field notes were taken during and after the interviews with notable non-verbal interactions and points of interest to be considered during the data analysis and interpretation.

Clinical psychologists were first asked about how they use computers in their current practice and what they thought about computerised therapy programmes in the context of their work with people with ID and in general. The interviewer (LV) asked clinicians about things that a computer programme would be good at, what they would expect from a computerised therapy package for people with ID and what the role of the therapist would be. Although the interviewer used some starter questions, she followed the flow of the conversation and used further questions and prompts flexibly to encourage clinicians to elaborate and clarify their viewpoints. This approach enabled the interviewer to elicit sufficient information about clinicians' expectations and concerns that may influence the implementation of computerised therapies in routine practice.

Interviews with service users explored (a) their access to and use of computer technologies in every day life, and (b) their general attitude towards using computers for therapy rather than entertainment. Prior to asking service users about computers in therapy, the interviewer checked what service users understood by the term "therapy" and how they usually coped with distress, anger or sadness. Following up on this, the interviewer asked about how computers can be used in therapy, what is important for the service users when they want help for emotional problems and how they think the therapist and the computer can help them. 


\section{Data Analysis}

The interviews were transcribed verbatim and the transcripts were anonymised. One researcher (LV) carried out the initial coding of all the transcribed interviews, as described by Braun and Clark (2006). This involved repeated readings of the transcripts, noting of preliminary codes and patterns of interest, and naming of the emergent codes. Following the assignment of the initial codes, these were compared according to their distinctiveness and consequently either collated into a higher-order code, or reworked into new distinct codes that would better reflect their content.

The second phase of the analysis followed a deductive process of sorting and re-sorting the different codes into potential themes independently by a second researcher (LG) whose specialist area is computerised therapies. The second researcher had access to the anonymised transcripts and the first stage coding. This process entailed adding and modifying codes, and repeatedly reviewing the emergent codes to compare the themes between service users and clinicians. Preliminary themes were reworked, collapsed, separated or removed until a coherent and consistent "story" emerged.

We used excerpts from transcripts to illustrate our final themes and to demonstrate that our conclusions were grounded in the narrative data. The excerpts were recorded verbatim and therefore report the terms 'learning disabilities' and 'people with LD', which are commonly used in the United Kingdom to describe people with ID in line with the diagnostic criteria in the ICD-10 (World Health Organisation, 1992).

We paid particular attention to participant accounts that departed from the common themes between service user and clinicians to ensure that all views and variations in the data were represented.

\section{Ethics}

Following permission from the responsible care coordinator, the lead researcher (LV) approached potentially eligible participants among service users in a day centre who knew LV already because they had previously taken part in a computerised therapy skills training session that she had facilitated. LV handed out a study information sheet and a consent form, which were written in easy to read language, detailing the study aims, design and procedures. This information was also verbally explained by LV who then asked questions to ensure service users fully understood the study procedures and their rights as a potential participant. LV also provided interested clinicians with a study information sheet and a consent form, and invited them to ask questions before agreeing to participate. Participants were reassured that all data would be anonymised if quotes from their interviews were published. On a return visit to the day centre, LV obtained written informed consent from both service users and clinicians who agreed to participate.

The study did not employ covert observation, randomisation, invasive procedures or procedures that could carry a risk of harm to the participants. Service users and clinicians who gave written consent for their interviews to be recorded could still withdraw at any point before or during the interview. Digital recordings were wiped clean once they were transcribed; transcripts were anonymised and did not include any identifying information.

This study was given a favourable ethical opinion by the National Research Ethics Committee in the UK (NRES 14/WS/1006). Approval was also granted by the relevant department of the local NHS Trust where the data collection took place.

\section{Results}

\section{Participants' Computer Use}

All three service users had access to computer technologies (desktop, laptop or tablet) and owned a smartphone. They used the internet to access social media, online games, multimedia and email, "...like write letters or make a card or listening see what's new films and see what's the weather like this week and watch music I like and sending email to my friends or families..." (User 1). 
None of the interviewed clinical psychologists used computers for substantial therapeutic functions in their routine practice. One clinician used computers to communicate for administrative purposes: "some of our young people [...] are more comfortable emailing us and communicating with us via email especially initially when we're getting to know them" (Clinician 3). The same clinician played non-therapeutic games to engage the children: "we play lots of computer games with children on their own computers as a part of engagement but not in terms of using [them] clinically in therapy..." (Clinician 3). Another clinician used a tablet to show videos around therapeutic concepts: "It was some videos on YouTube [...] that I thought might be quite useful to describe metaphors from acceptance and commitment therapy" (Clinician 1).

\section{Common Themes between Service Users and Clinicians}

Six common themes emerged from the views of clinicians and service users on integrating computers in psychological therapy for people with ID: confidentiality, communication, value of therapist, access, engagement, and home practice.

Table 3. Service User and Clinician Views on Computers in Therapy for People with Intellectual Disabilities (ID).

\section{Common themes between service Service users Clinicians} users and clinicians

\section{Confidentiality}

2. Communication

\section{Value of therapist}

4. Access

\section{Engagement}

\section{Home practice}

Aware of dangers of sharing personal information online and need assurance of privacy and confidentiality

Overcoming barriers with verbal communication; alleviating discomfort when speaking to a therapist

Talk to people face-to-face and be listened to.

Positive approach - people with ID have access to different forms of digital technology, know to use it and like it.

Touch screen and keyboard and mouse; pictures, symbols and sign language; games.

Diary easier to write down on tablet and then bring it back to therapy and discuss it.
Concerned that service users are not aware of dangers of online information sharing

Alleviating discomfort when speaking to a therapist

Build rapport, respond to changing needs, deal with distress, address social care needs. Cautious approach - barriers for clinicians who may not have access to IT or are technophobic or techno-agnostic

Touch screen, pictures, symbols, verbal and sign language, relevant and customisable scenarios

Thought record easier by pressing buttons; doing therapeutic tasks independently

1. Confidentiality: Clinicians highlighted potential confidentiality threats as they believed that people with ID would be more vulnerable to breaches of confidentiality by technology-mediated exchange of information.

"So obviously issues around consent would be important. So it's really important that the person doing the computerised stuff knows that the content is about thoughts and feelings and that might then be shared if they were to involve somebody else in that process." (Clinician 2)

"I suppose as people do therapy using computers and they would be filling in just mood diaries or doing a test online and sharing that with you, where is everything saved? I think that would be my concern. People with learning disabilities wouldn't worry too much about, I think they might not have the awareness." (Clinician 3) 
Service users were aware of the dangers of sharing personal information online: "Have to be careful on Facebook." (User 2). One participant required reassurance that private information would not be exposed:

"Someone might be thinking what they say. That is why I say something really private, I don't want that on a computer 'cause it might send it out to people to see it [...] Would be alright if computer can keep it secret." (User 1)

2. Communication: Service users and clinicians shared the same view on the value of computers for enabling non-verbal communication, the expression of emotions and abstract concepts, and feeling less intimidated, especially if the therapist is not someone the person feels comfortable with. "You can communicate with computer. Like if you write things down on the computer maybe psychologist write it down on computer what you said, then the computer might understand a bit what you were saying." (User 1). Computers could be used in therapy to answer questions, either by writing, clicking or drawing: "I'd draw a circle and what colour I want. It's like dark colour, me, I feel sad. Light colour, I feel happy." (User 2).

Overcoming initial discomfort in talking to a relative stranger is important for service users: "It's sometimes very difficult to talk to somebody because you never met them before and because they're not everyone's thing." (User 1). The gender of the therapist was also reported as important by our participating service users, who had experienced therapy before and favoured a female therapist to talk to: "Some people, when I talk to you, I like to talk to lady, like you, you're not men. If I talk to men, I find that really difficult if I talk to men and doctors men." (User 2); "I think female more understand what I'm saying." (User 1)

By focusing on the computer for part of the time, therapeutic computer programmes can defuse the potential build-up of tension and anxiety associated with therapy. Therapeutic contact may initially feel uncomfortable for clients and using computers in therapy could motivate a client to attend therapy while gradually building a trusting environment. "People with learning disabilities can be a bit scared of talking sometimes and it takes the focus away a bit. It's (the computer) quite useful because it makes it a bit less intense." (Clinician 1). This echoes the view of another clinician:

"I can think of a number of people who would quite happily sit next to me and work at a computer screen and would find that much more comfortable than sit in a room and not knowing whether to look at me and what to do." (Clinician 2).

3. Need for a therapist: Both parties agreed on the potential danger of the computer becoming a "gimmick" that dilutes the relationship with a therapist. Clinicians raised the issue that therapy should not be solely focused on a computer or on training people in specific skills, but also on validating patients' experiences and building a therapeutic alliance.

"The empathic side and the listening side and the making sense of stuff side. [...] It's also about validating how someone's, you know, their experience and paying attention to those. And I suppose that that might be a slight drawback [of computers]." (Clinician1)

When faced with mental health problems, support from talking face-to-face to a therapist would be preferred over seeking help online or working with a computer: "Computers is OK, but therapy... you have to talk to people face to face when problems you've got." (User 2). Being listened to was also an important aspect of seeing a therapist: "Listen. Listen to my problems, how I felt, how I feel, why I feel like that, why I feel scared. Mixed up emotions, you just want to talk to someone and I need someone to talk to sometimes." (User 2)

Clinicians saw themselves as facilitators and motivators for using computers in therapy and saw computers as a tool for clinician-delivered interventions and not self-help: "I'd hope to use it in a way that wasn't necessarily as an instructor. [...] I suppose it would be perhaps as a facilitator." (Clinician 1). Doubt was expressed regarding the use of computers in therapy without a personalised approach for people who have complex emotional and social needs: 
“People in very aversive environment or circumstances [...] That's where we can usually put in our social care colleagues and you can pull that person out [...] I think it could be a bit invalidating if someone's in quite not a nice place to be get your computer out and you know doing all these tasks with them." (Clinician 1)

"We wouldn't be in a position where we have a referral for a young person who has some difficulties and is very distressed at the moment therefore we deliver a computerised programme. That's not what psychologists do and that's not formulation." (Clinician 2).

Furthermore, clinicians spoke of the balance between skills-based computer programmes and maintaining an effective therapeutic relationship. The concern about patients building rapport with the computer was raised and clinicians concluded that a collaborative approach should be taken.

"I think you still need skilful therapists to deal and to deal with anything that comes up and address that with the client. It's not a mechanical process, it can't be. [...] Now, where as a clinician you make those decisions along the way and when you've got steps in a digital programme, how things would be predictive: if that, do that, if that, do that. [...] Now I'm starting to think about rapport: Is the client going to build rapport with you or with the laptop? I'd like to think that especially for therapy, you would still need skilful experienced clinicians." (Clinician 3)

4. Access: Service users with ID were positive about their ability to access computers: "Many people can do [use computers]" (User 1); "I take my tablet with me" (User 2). Also people with ID learn how to work with computers in college or at a day service: "I learned IT at [day service name]" (User 2); "Yes, they all do." (User 3).

On the contrary, clinicians expressed concerns about logistical issues with the provision of, and responsibility for, the necessary hardware and software "[f]or clients to have access to things if we are using it as part of homework." (Clinician 3) and for staff to have the necessary time and skills:

"With an iPad, a laptop perhaps, taking that around everywhere, starting it up, you know, five minutes for it to load up and everything. And software, you know, are they compatible [...] I think there are some sort of financial difficulties with that, yes." (Clinician 1)

“... we are a service that works on electronic health records so we've had lots of difficulties with accessing them from other places and being out in the community and needing computers but not getting access. [...] I think staff can feel a bit overwhelmed and feel that it's a bit too technical and therefore not ever quite get to using it..." (Clinician 2)

5. Engagement: Clinicians and service users shared the view that the versatility in the presentation and access of materials via a computer is an advantage for engaging people with ID in therapy. A service user suggested that therapists could use the computer to play games to make therapy more fun and less difficult: "With tablet. [...] Play games. With the therapist." (User 3). Clinicians also mentioned that computer tasks would have to be interactive and dynamic to facilitate user engagement.

"Where the current packages are limited, as far as these things go at the moment, it's on paper or you've got worksheets. [...] On a CD-ROM, in a way, you've got sort of an electronic version of the paper stuff, but that's all very static. I think that is where the computerised programmes can come in because these things have moving images." (Clinician 3)

The visual appeal of computer programmes is preferable over verbal explanations and black and white drawings:

"I think that a lot of the materials for children and young people are very boring so black and white sheets you know quite mechanical drawings and not necessarily something that's engaging and grabs their interest so yeah something that something that looks appealing and engaging as well." (Clinician 2) 
One clinician noted that combining photographic and computer technologies could prove more time-efficient:

'You're standing at the bus stop', so you've got that bus stop image. Are you able to photoshop, you know, in a way the person into it because then they're standing at the bus stop. [...] Things like that will be helpful instead of going out and taking photos of all these places that you need with the client actually in them." (Clinician 3)

Clinicians mentioned various requirements for both the presentation of computerised materials and the means by which users can access them: "Obviously as many pictures as possible." (Clinician 1); "Using symbols and signing" (Clinician 2); "Touch screens would really work." (Clinician 3).

"Language that is presented in a way that makes sense to that individual [...] whether that's a computerised voice or a recording of their own voice or a parent's voice or somebody's voice that they understand and that they know well." (Clinician 2).

Service users also suggested that information is presented in a range of formats, such as "pictures for learning." (User 1) and sign language "If someone is deaf like my friend and hard understand people, if can't read lips use sign language." (User 2). Service users recognised the varying needs and preferences of people with ID in accessing information. One interviewee said: "Now I prefer the touch screen." (User 2), whereas another highlighted the value of using a keyboard and mouse.

"Sometime people like to use the keyboard or somebody that use the mouse. If somebody can't use, sometime their hand is a problem, and that someone you can help with the mouse to move things around and they can feel, as well."(User 1)

All three clinicians identified that computer programmes need to provide a suite of materials that can be selected according to patients' preferences, personal relevance and intellectual level, or adapted to suit individual needs and circumstances: "If there were things that you could then tailor a little bit [...] (something) that might be more relevant to the person and something that's happened in their life." (Clinician 1); "If it is around the cognitive mediation sort [...] absolutely it would need to be situations that were relevant to that person." (Clinician 2).

“Generating scenarios that are appropriate [...] making it relevant to the person you're working with. [...] You have to be able to customise it. [...] When you start using it in a therapeutic way, there needs to be quite a lot of flexibility" (Clinician 3)

5. Home practice: In CBT, homework tasks between sessions are often used as means to help people transfer their skills from the therapy room to their every day life and to learn things that they can then discuss in therapy. A computer could be particularly useful for the completion of such homework tasks. "I think it would be helpful [...] to be more independent in doing the therapy. I think that might help people to actually do it on their own and actually do it." (Clinician 3)

"Perhaps with things like CBT, in homework tasks it can be much easier if there was an app on an iPad or something for a homework task. That might be a lot easier for someone to achieve, like pressing a few buttons, than it would perhaps writing out a thought record." (Clinician1)

"If some people like have fun, they like go out with your friends and things, some people just write them down, and things like that, what have you done today, what are you doing today, what are you up to. Just write down in the diary." (User 2)

\section{Additional Themes}

Three additional themes emerged from clinician responses: suitability, distrust and involving a third party.

1. Suitability: Clinicians emphasised the potential benefits of computer programmes in teaching service users about emotional states such as "(I)earning about the difference between assertive, and aggressive, and passive." 
(Clinician 3) and in helping service users recognise and regulate different emotions: "(A programme) for identifying, recognising and understanding emotions. [...] So many people can distinguish between I feel OK or I don't feel OK, but perhaps separating between whether that's cross or sadness or worry." (Clinician 2)

"I think that the CBT type approach via computer could work really well for [...] what I would describe as someone who has difficulties in regulating their own emotions: so somebody who has periods of distress and has difficulty recognising that and regulating that." (Clinician 2)

When considering the application of computer programmes in therapy with specific mental health problems, clinicians suggested that computerised applications would lend themselves well to "...problem solving, I think, that would fit quite well." (Clinician 3); "Anxiety I think would be a huge one which would probably [...] be most useful to start with." (Clinician 2); "I think certainly mild to moderate anxiety and depression would be [...] a good use of computerised CBT for people with learning disabilities" (Clinician 1).

2. Distrust: Clinicians appeared wary as to whether other clinicians would welcome computers in the context of therapist-delivered interventions: "If we carry on like that, then there's no need for us anymore. They can use it and fix it by the computer or therapy." (Clinician 3). In addition, one clinician highlighted that staff may require technical training and may distrust computers, something that should be acknowledged and addressed:

"I think people (staff) might get a bit anxious and say 'oh gosh, that's not right for people with learning disabilities [...]'l think there'll be some resistance from people wondering if this was a shift away from individual delivering therapy and a shift toward delivering manualised therapy via a computer. [...] I think in the current climate in the NHS (National Health Service) people are worried [...] that it might be a cost cutting exercise." (Clinician 2)

3. Involving a third party: Computer programmes might make the therapy process accessible to supporting third parties, such as carers, who may use them to gain a better understanding of both the processes involved in therapy and the experiences of the person with ID they are supporting:

"The carers or the family and teachers, whoever it might be, often benefit from having a greater understanding of what that person's thought processes are. So often the descriptions are around behaviour and focusing on a CBT type model. People have a greater understanding if actually this is how they're interpreting the world, this is how they're seeing the world. And that's really important in how they support that person." (Clinician 2)

\section{Discussion}

To our knowledge, there are no other studies to-date exploring and comparing the views of service users and clinicians as to how we can integrate computers in therapy for people with ID. The responses from our participating clinicians reflected their general opinion and expectations of computers in therapy, whereas service user views were informed by their experience of having previously participated in computerised training in CBT skills (Vereenooghe et al., 2016).

This was an exploratory study with a small sample that was not representative of all service users with ID or all clinicians working in the field. The study did not aim to reach data saturation but to provide some anchor points for the development of computer programmes and interview topic guides for future studies. Our emerging themes are a starting point for generating hypotheses and building a framework for integrating computers in therapy for people with ID.

Our participating service users and clinicians saw computers as valuable in helping people with ID overcome verbal communication barriers, either due to their physical disability or due to the anxiety of speaking to a therapist whom they do not know or do not like. Service users and clinicians shared the idea that computers can be used to facilitate homework completion, and that on-screen pictures, sign language, symbols and touchscreen were important design features in a computer programme that wanted to engage service users. 
Previous studies reported the particular benefits of using computers in therapy with people with ID in terms of increasing their willingness to engage in individual therapy because interactive techniques promote a sense of ownership and motivation to change (Rose, West, \& Clifford, 2000). People without ID indicated that the benefits and value of computerised therapy programmes were in increasing their insight into their mental health problems, improving their knowledge and understanding of CBT, teaching them therapy skills and techniques (Bendelin et al., 2011; Gega, Smith, \& Reynolds, 2013) and helping them feel empowered (Knowles et al., 2014).

Our study participants raised the issue of confidentiality as a key challenge to using computer programmes in therapy. Interestingly, clinicians were concerned that people with ID would not be aware of computer threats to confidentiality, whereas the interviewed service users demonstrated exactly this: their awareness of confidentiality issues arising from information sharing via a computer.

Another difference between the views of service users and clinicians was in the theme of "access". Our service users stated that people with ID have easy access to computers and the skills to use them. This is consistent with previous research demonstrating that people with ID are able to use and enjoy computer technologies for a wide range of purposes (Carey, Friedman, \& Bryen, 2005). On the contrary, our participating clinicians expressed concerns about their own capacity and capability to access and use computers in therapy. An important barrier to the integration of computers in therapy for people with ID is clinician distrust towards computers as a substandard option driven by financial motives and not by therapeutic reasons. This chimes with other literature, reviewed by Chadwick, Wesson, and Fullwood (2013), which indicates that clinicians who support people with ID hold negative or suspicious attitudes towards internet use, often influenced by their own lack of knowledge and skills in this area. Such attitudes stem from beliefs that computers are beyond the skills and capacity of people with ID or that the internet reinforces social isolation as it can become a barrier to interpersonal contact.

Both service users and clinicians underscored the value of the "person" in the context of using computers in therapy. For service users, this was because the therapist could speak and listen to them. For clinicians, this was wrapped around their professional role ("...deliver a computerised programme. That's not what psychologists do...") and the inherent value they attach to the therapeutic relationship (Is the client going to build rapport with you or with the laptop?). Clinicians in our study aptly described situations where a computer cannot fulfil the role of a therapist in terms of addressing social care needs or being able to respond to a service user's change of emotional state or circumstances. Clinicians also provided useful insights as to which conditions or interventions may be more suitable for computerised delivery, including anxiety, depression, problem-solving, assertiveness training and differentiating between emotional states.

In routine clinical practice, we should distinguish between using computers as a tool for clinician-delivered therapy and using computers as a "self-help" intervention with adjunct therapist support. This is noteworthy in light of the small effects of media-delivered CBT as a self-help intervention for the general population (MayoWilson \& Montgomery, 2013), especially when offered without therapist support (Cuijpers et al., 2011). Furthermore, the high attrition rates reported for computerised self-help suggest that such interventions might be more useful as an additional therapeutic tool rather than as a standalone intervention (Twomey et al., 2014). Finally, clinicians working in mainstream mental health services are more receptive towards using computers as an adjunct to face-to-face therapy rather than as a standalone intervention (Stallard, Richardson, \& Velleman, 2010; Wangberg, Gammon, \& Spitznogle, 2007; Whitfield \& Williams, 2004).

The interviewed clinicians provided an insightful view that standardised materials in computerised therapy programmes are inadequate unless they offer a comprehensive menu of scenarios and audio-visual aids to meet the different clinical presentations, intellectual abilities and preferences of their service users. This comment is important because it pre-empts an important limitation of computerised therapy: the generic standardised materials that do not address the person's specific needs and circumstances (Gega et al., 2013; Hind et al., 2010)

A clinician touched upon the possibility of involving a third party, such as carers or teachers, when using computers in therapy. This is important not only because carers enable people with ID to access therapy services, but also because carers can help the communication between the therapist and the person with ID 
(Department of Health, 2009; Hurley et al., 1998; Royal College of Psychiatrists, 2004) and enhance therapy effects (Rose, Loftus, Flint, \& Carey, 2005).

A theoretical understanding of our results is underpinned by the socio-ecological model of disability, i.e. impaired functioning is not a personal deficit trait but the result of enabling or disabling societies and environments (Wehmeyer et al., 2008). Computers may be a way of overcoming perceived and real barriers for people with ID accessing therapy, especially as their mental health needs are greater than those of the general population but their access to mainstream therapy services is limited. Evidence summarised by Chadwick et al. (2013) suggests that a digital divide exists for people with ID who could potentially stand to gain the most from computer technology, but are the least likely to gain access to it and receive the full benefits from it. In this context, limited access to therapy is not the result of cognitive impairment that makes it difficult for people with ID to use mainstream services, but the result of services failing to use technology that makes therapy more accessible for people with ID.

\section{Implications for Research and Practice}

Computers and digital technologies in general, including tablets and smart-phones, may be the means of supporting therapy and improving access to it for people with ID who are usually excluded from mainstream services. Although we need to take into account the special circumstances and needs of people with ID, we can still use in practice what we have learnt from integrating computers in therapy for the general population. One of our participating clinicians captured this point:

"I think it's good that people are talking and researching computerised therapy for people with learning disabilities and that they're not excluded. I also think that it's good that there's a recognition that the impact of the disability means that we might need to do things slightly different but we might not. We shouldn't assume that we always have to do things differently either. "(Clinician 2)

The implementation of computer programmes in therapy for people with ID would require clinicians to be wellinformed and confident in using these technologies. Successful involvement of carers also requires that the family has access to appropriate technology and training about how they can enable the children or adults with ID whom they look after to use this technology for therapeutic purposes (Palmer, Wehmeyer, Davies, \& Stock, 2012).

Further developments of digital technologies for people with ID should follow a close collaboration between researchers, practitioners, people with ID themselves and their carers/families, so that the design and application of such technologies are fit for therapeutic purposes (Wehmeyer, Smith, Palmer, \& Davies, 2004). In addition, mainstream research into computerised therapies needs to involve adaptive designs that are accessible to people with ID who should no longer be excluded by default from large clinical trials (The United Nations, 2006).

\section{Acknowledgement}

Peter E. Langdon is supported by a National Institute for Health Research Postdoctoral Fellowship (Grant Reference: NIHR-PDF-2011-04-040).

\section{References}

Andersson, G. (2009). Using the internet to provide cognitive behaviour therapy. Behaviour Research and Therapy, 47, 175-180. http://doi.org/http://dx.doi.org/10.1016/j.brat.2009.01.010

Bendelin, N., Hesser, H., Dahl, J., Carlbring, P., Nelson, K. Z., \& Andersson, G. (2011). Experiences of guided internet-based cognitive-beahvioural treatment for depression: A qualitative study. BioMed Central Psychiatry, 11, 107-116. http://doi.org/10.1186/1471-244X-11-107 
Bhaumik, S., Tyrer, F. C., Mcgrother, C., \& Ganghadaran, S. K. (2008). Psychiatric service use and psychiatric disorders in adults with intellectual disability. Journal of Intellectual Disability Research, 52, 986-995.

http://doi.org/10.1111/j.1365-2788.2008.01124.x

Braun, V., \& Clarke, V. (2006). Using thematic analysis in psychology. Qualitative Research in Psychology, 3, 77-101. http://doi.org/10.1191/1478088706qp063oa

Burke, C.-K. (2014). Feeling down: Improving the mental health of people with learning disabilities. London: Foundation for People with Learning Disabilities.

Carey, A. C., Friedman, M. G., \& Bryen, D. N. (2005). Use of electronic technologies by people with intellectual disabilities. Mental Retardation, 43, 322-333. http://doi.org/10.1352/0047-6765(2005)43[322:UOETBP]2.0.CO;2

Chadwick, D., Wesson, C., \& Fullwood, C. (2013). Internet access by people with intellectual disabilities: Inequalities and opportunities. Future Internet, 5, 376-397. http://doi.org/10.3390/fi5030376

Chinn, D., Abraham, E., Burke, C.-K., \& Davies, J. (2014). IAPT and Learning Disabilities. London: Foundation for People with Learning Disabilities.

Cooper, S., Smiley, E., Morrison, J., Williamson, A. W., \& Allan, L. (2007). Mental ill-health in adults with intellectual disabilities: Prevalence and associated factors. British Journal of Psychiatry, 190, 27-36.

http://doi.org/10.1192/bjp.bp.106.022483

Cuijpers, P., Donker, T., Johansson, R., Mohr, D. C., van Straten, A., \& Andersson, G. (2011). Self-guided psychological treatment for depressive symptoms: A meta-analysis. PLOS ONE, 6(6).

http://doi.org/10.1371/journal.pone.0021274

Dagnan, D., Mellor, K., \& Jefferson, C. (2009). Assessment of cognitive therapy skills for people with learning disabilities. Advances in Mental Health \& Learning Disabilities, 3(4), 25-30.

http://doi.org/http://dx.doi.org/10.1108/17530180200900036

Dattilo, J., Williams, R., \& Cory, L. (2003). Effects of computerized leisure education on knowledge of social skills of youth with intellectual disabilities. Therapeutic Recreation Journal, 37, 142-155.

Department of Health. (2009). Learning Disabilities: Positive Practice Guide. London: Department of Health.

Emerson, E., \& Hatton, C. (2007). Mental health of children and adolescents with intellectual disabilities in Britain. The British Journal of Psychiatry, 191, 493-499. http://doi.org/10.1192/bjp.bp.107.038729

Gega, L., Smith, J., \& Reynolds, S. (2013). Cognitive behaviour therapy (CBT) for depression by computer vs. therapist: Patient experiences \& therapeutic processes. Psychotherapy Research, 23, 218-231.

http://doi.org/http://dx.doi.org/10.1080/10503307.2013.766941

Hind, D., O'Cathain, A., Cooper, C. L., Parry, G., Isaac, C. L., Rose, A., ... Sharrack, B. (2010). The acceptability of computerised cognitive behavioural therapy for the treatment of depression in people with chronic physical disease: A qualitative study of people with multiple sclerosis. Psychology and Health, 25, 699-712.

http://doi.org/http://dx.doi.org/10.1080/08870440902842739

Hurley, A. D., Tomasulo, D. J., \& Pfadt, A. G. (1998). Individual and group psychotherapy approaches for persons with mental retardation and developmental disabilities. Journal of Developmental and Physical Disabilities, 10, 365386. http://doi.org/10.1023/A:1021806605662

Joyce, T., Globe, A., \& Moody, C. (2006). Assessment of the component skills for cognitive therapy in adults with intellectual disability. Journal of Applied Research in Intellectual Disabilities, 19, 17-23.

http://doi.org/10.1111/j.1468-3148.2005.00287.x

Knowles, S. E., Toms, G., Sanders, C., Bee, P., Lovell, K., Rennick-Egglestone, S., ... Gilbody, S. (2014). Qualitative meta-synthesis of user experience of computerised therapy for depression and anxiety. PLoS One, 9(1), e84323. http://doi.org/http://dx.doi.org/10.1371/journal.pone.0084323

Mayo-Wilson, E., \& Montgomery, P. (2013). Media-delivered cognitive behavioural therapy and behavioural therapy (self-help) for anxiety disorders in adults. The Cochrane Database of Systematic Reviews, 9(9), CD005330.

http://doi.org/10.1002/14651858.CD005330.pub4 
Mesa, S., \& Tsakanikos, E. (2014). Attitudes and self-efficacy towards adults with mild intellectual disability among staff in acute psychiatric wards: An empirical investigation. Advances in Mental Health and Intellectual Disabilities, 8, 79-90. http://doi.org/10.1108/AMHID-02-2013-0011

Newby, J. M., Twomey, C., Li S. Y. \& Andrews, G. (2016). Transdiagnostic computerised cognitive behavioural therapy for depression and anxiety: A systematic review and meta-analysis. Journal of Affective Disorders, 199, 3041. http://doi.org/10.1016/j.jad.2016.03.018

Oathamshaw, S. C., \& Haddock, G. (2006). Do people with intellectual disabilities and psychosis have the cognitive skills required to undertake cognitive behavioural therapy? Journal of Applied Research in Intellectual Disabilities, 19, 35-46. http://doi.org/10.1111/j.1468-3148.2005.00284.x

Palmer, S. B., Wehmeyer, M. L., Davies, D. K., \& Stock, S. E. (2012). Family members' reports of the technology use of family members with intellectual and developmental disabilities. Journal of Intellectual Disability Research, 56, 402-414. http://doi.org/10.1111/j.1365-2788.2011.01489.x

Pennant, M. E., Loucas, C. E., Whittington, C., Creswell, C., Fonagy, P., Fuggle, P., ... Williams, P. (2015). Computerised therapies for anxiety and depression in children and young people: A systematic review and meta-analysis. Behaviour Research and Therapy, 67, 1-18. http://doi.org/10.1016/j.brat.2015.01.009

Reed, J., \& Clements, J. (1989). Assessing the understanding of emotional states in a population of adolescents and young adults with mental handicaps. Journal of Intellectual Disability Research, 33, 229-233.

http://doi.org/10.1111/j.1365-2788.1989.tb01470.x

Richards, D., Richardson, T., Timulak, L., \& McElvaney, J. (2015). The efficacy of internet-delivered treatment for generalized anxiety disorder: A systematic review and meta-analysis. Internet Interventions, 2, 272-282.

http://doi.org/10.1016/j.invent.2015.07.003

Rose, J. L. (2013). A preliminary investigation into the influence of therapist experience on the outcome of individual anger interventions for people with intellectual disabilities. Behavioural and Cognitive Psychotherapy, 41, 470-478. http://doi.org/https://doi.org/10.1017/S1352465812000823

Rose, J. L., Loftus, M., Flint, B., \& Carey, L. (2005). Factors associated with the efficacy of a group intervention for anger in people with intellectual disabilities. British Journal of Clinical Psychology, 44, 305-317.

http://doi.org/10.1348/014466505X29972

Rose, J. L., West, C., \& Clifford, D. (2000). Group interventions for anger in people with intellectual disabilities. Research in Developmental Disabilities, 21, 171-181. http://doi.org/10.1348/014466505X29972

Royal College of Psychiatrists. (2004). Psychotherapy and learning disability. Council report: CR116. London.

Schalock, R. L., Luckasson, R. a, Shogren, K. a, Borthwick-duffy, W. S., Bradley, V., Buntinx, W. H. E., ... Yeager, M. $\mathrm{H}$. (2007). The renaming of mental retardation: Understanding the change to the term intellectual disability. Intellectual and Developmental Disabilities, 45, 116-124. http://doi.org/10.1352/1934-

9556(2007)45[116:TROMRU]2.0.CO;2

Stallard, P., Richardson, T., \& Velleman, S. (2010). Clinicians' attitudes towards the use of computerised cognitive behaviour therapy (CCBT) with children and adolescents. Behavioural and Cognitive Psychotherapy, 38, 545-560. http://doi.org/https://doi.org/10.1017/S1352465810000421

Standen, P. J., \& Brown, D. J. (2005). Virtual reality in the rehabilitation of people with intellectual disabilities: Review. CyberPsychology \& Behavior, 8, 272-282. http://doi.org/10.1089/cpb.2005.8.272

Taylor, J. L., \& Knapp, M. (2013). Mental health and emotional problems in people with intellectual disabilities. In J. L. Taylor, W. R. Lindsay, R. P. Hastings, \& C. Hatton (Eds.), Psychological therapies for adults with intellectual disabilities (pp. 1-14). Oxford: John Wiley \& Sons Ltd.

The United Nations. (2006). Convention on the Rights of Persons with Disabilities. Retrieved from http://www.ohchr.org/EN/HRBodies/CRPD/Pages/ConventionRightsPersonsWithDisabilities.aspx 
Twomey, C., O'Reilly, G., Byrne, M., Bury, M., White, A., Kissane, S., ... Clancy, N. (2014). A randomized controlled trial of the computerized CBT programme, MoodGYM, for public mental health service users waiting for interventions. British Journal of Clinical Psychology, 53, 433-450. http://doi.org/10.1111/bjc.12055

Vereenooghe, L., Gega, L., Reynolds, S., \& Langdon, P. E. (2016). Using computers to teach people with intellectual disabilities to perform some of the tasks used within cognitive behavioural therapy: A randomised experiment. Behaviour Research and Therapy, 76, 13-23. http://doi.org/10.1016/j.str.2014.12.012

Vereenooghe, L., \& Langdon, P. E. (2013). Psychological therapies for people with intellectual disabilities: A systematic review and meta-analysis. Research in Developmental Disabilities, 34, 4085-4102.

http://doi.org/10.1016/j.ridd.2013.08.030

Vereenooghe, L., Reynolds, S., Gega, L., \& Langdon, P. E. (2015). Can a computerised training paradigm assist people with intellectual disabilities to learn cognitive mediation skills? A randomised experiment. Behaviour Research and Therapy, 71, 10-19. http://doi.org/10.1016/j.brat.2015.05.007

Wangberg, S. C., Gammon, D., \& Spitznogle, K. (2007). In the eyes of the beholder: Exploring psychologists' attitudes towards and use of e-therapy in Norway. CyberPsychology \& Behavior, 10, 418-423.

http://doi.org/10.1089/cpb.2006.9937

Wehmeyer, M. L., Buntinx, W. H., Lachapelle, Y., Luckasson, R. A., Schalock, R. L., \& Verdugo, M. A. (2008). The intellectual disability construct and its relation to human functioning. Intellectual and Developmental Disabilities, 46, 311-318. http://doi.org/http://dx.doi.org/10.1352/1934-9556(2008)46[311:TIDCAI]2.0.CO;2

Wehmeyer, M. L., Smith, S. J., Palmer, S. B., \& Davies, D. K. (2004). The effect of student-directed transition planning with a computer-based reading support program on the self-determination of students with disabilities. Journal of Special Education Technology, 19, 7-22.

Whitehouse, R. M., Tudway, J. A., Look, R., \& Stenfert-Kroese, B. (2006). Adapting individual psychotherapy for adults with intellectual disabilities: A comparative review of the cognitive-behavioural and psychodynamic literature. Journal of Applied Research in Intellectual Disabilities, 19, 55-65. http://doi.org/10.1111/j.14683148.2005.00281.x

Whitfield, G., \& Williams, C. (2004). If the evidence is so good - why doesn't anyone use them? A national survey of the use of computerized cognitive behaviour therapy. Behavioural and Cognitive Psychotherapy, 32, 57-65. http://doi.org/https://doi.org/10.1017/S1352465804001031

Willner, P. (2006). Readiness for cognitive therapy in people with intellectual disabilities. Journal of Applied Research in Intellectual Disabilities, 19, 5-16. http://doi.org/10.1111/j.1468-3148.2005.00280.x

World Health Organisation. (1992). ICD-10 Classifications of mental and behavioural disorder: Clinical descriptions and diagnostic guidelines. Geneva, Switzerland.

\section{Correspondence to:}

Dr Leen Vereenooghe

Department of Psychology

Bielefeld University

Postfach 100131

D-33501 Bielefeld

Email: leen.vereenooghe@uni-bielefeld.de 


\section{About Authors}

Dr Leen Vereenooghe is junior Professor of Psychological Interventions in Inclusive Settings at the University of Bielefeld, Germany. Her research interests are related to promoting the mental well-being of people with disabilities and the role of new technologies.

Dr Lina Gega is a Reader in Mental Health at the University of York, United Kingdom. She is a nurse and a cognitive behaviour therapist with a track record in computerised therapies and virtual environments. Her current research is with children and young people who experience, or are at risk of, mental health problems.

Dr Peter Langdon is a Senior Lecturer in Clinical Psychology and Disability at the University of Kent, United Kingdom, and also works as an Honorary Consultant Clinical and Forensic Psychologist. His research focuses on group cognitive behavioural therapy for people with Asperger Syndrome and high functioning autism who also have problems with anxiety, and on hospital care pathways for people with autistic spectrum conditions.

Editorial record: First submission received on January 11, 2016. Revision received on January, 5, 2017. Accepted for publication on May 5, 2017. The article is part of Special Issue "Internet use and disability - Risks, opportunities and challenges" guest edited by Emma Sorbring and Martin Molin. 